\title{
Analisis kekuatan tarik, bending, mikrostruktur, komposisi dan kemampuan redam suara komposit serat pelepah pisang menggunakan metode Vacuum Assisted Resin Infusion
}

\author{
Annisa Angelia*, Muhammad Abdul Ghofur, Arif Djoko Nugroho, Purwadi, \\ Purnomo Herlambang \\ Prodi Teknik Aeronautika Pertahanan, Akademi Angkatan Udara, Yogyakarta, Indonesia \\ Email Korespondensi : "nisaaji0101@gmail.com
}

\begin{abstract}
Abstrak. Komposit merupakan suatu material hasil rekayasa yang terdiri dari dua atau lebih material penyusunnya dimana material penyusun komposit terdiri dari penguat (reinforcement) dan pengikat (matrix). Salah satu jenis serat adalah serat alam yang sangat mudah ditemukan dikehidupan kita sehari-hari. Pelepah pisang adalah salah satu jenis serat alam yang memiliki jaringan selular dengan pori-pori yang saling berhubungan. Proses pembuatan spesimen komposit dalam penelitian ini menggunakan metode Vaccum Assisted Resin Infusion (VARI). Selanjutnya spesimen akan diuji dengan alat uji tarik dengan standar ASTM D 3039/ 3039 M dan alat uji bending dengan standar ASTM D790-03. Tujuan penelitian ini adalah untuk mengetahui kekuatan tarik, kekuatan bending, mikrostruktur dan komposisi dari komposit serat pelepah pisang antara komposit dengan waktu pengeringan selama 1 hari dan 7 hari. Selain itu dilakukan juga uji redam suara dari spesimen komposit tersebut yang kemudian dibandingkan dengan hasil uji redam suara dari glasswoll. Hasil dari penelitian ini diperoleh kekuatan tegangan tarik yang dihasilkan oleh komposit serat pelepah pisang dengan waktu pengeringan selama 7 hari adalah sebesar 17,90 $\mathrm{N} / \mathrm{mm}^{2}$ sedangkan waktu pengeringan selama 1 hari adalah sebesar $16,72 \mathrm{~N} / \mathrm{mm}^{2}$. Kekuatan bending yang dihasilkan oleh komposit serat pelepah pisang dengan waktu pengeringan selama 7 hari adalah sebesar 31,75 N/mm ${ }^{2}$ sedangkan waktu pengeringan selama 1 hari adalah sebesar 20,68 $\mathrm{N} / \mathrm{mm}^{2}$. Hasil mikrostruktur pada komposit serat pelepah pisang dengan waktu pengeringan selama 7 hari terlihat serat dan resin lebih menyatu dibandingkan waktu pengeringan selama 1 hari dimana serat dan resin kurang menyatu serta masih banyak ronga udara. Jumlah oksigen pada komposit serat pelepah pisang dengan waktu pengeringan selama 1 hari yaitu 52,00\% sedangkan waktu pengeringan selama 7 hari yaitu 51,35\%. Pada penelitian ini juga diperoleh hasil desibel suara tanpa adanya sekat atau ruangan kosong dengan diberi suara sebesar $103 \mathrm{~dB}$ sehingga dapat disimpulkan bahwa hasil uji peredam suara komposit pelepah pisang dengan waktu pengeringan selama 7 hari mampu meredam suara sebesar $21 \%$ dengan taraf intensitas suara 89,5 dB sedangkan glasswoll memberikan peredaman suara sebesar 8,76\% dengan nilai taraf intensitasnya $91,7 \mathrm{~dB}$.

Kata Kunci: Komposit, Serat pelepah pisang, Vacuum Assisted Resin Infusion, Sound level meter, Glasswooll, Uji tarik, Uji bending, Uji Mikrostruktur, Uji Komposisi, Uji peredam suara.
\end{abstract}

\section{Pendahuluan}

Komposit adalah suatu material hasil rekayasa yang terdiri dari dua atau lebih material penyusunnya yang memiliki sifat mekanik yang lebih bagus dari logam karena kekakuan jenis dan kekuatan jenisnya, dimana material penyusun komposit terdiri dari penguat (reinforcement) dan pengikat (matrix) (Kardiman, Marno,\& Joso Sumarjo 2018, h. 22). Berkembangnya metode pembuatan komposit yang lebih modern 
saat ini adalah menggunakan metode Vacuum Assisted Resin Inffusion (VARI). Metode Vacuum Assisted Resin Inffusion membutuhkan ruang kedap udara dalam pembuatannya yaitu penguat diletakkan didalam cetakan yang didesain dapat menghasilkan ruang kedap udara (M.Alfian, Salahuddin, \& Ahmad 2018, h.10). Sifat mekanik suatu komposit diketahui dengan pengujian tarik dan bending dimana sampel ditarik dan di tekan dengan pembebanan pada kedua ujungnya ditarik dan di tekan hingga putus dan patah dimana serat dan resin terurai. Serat dan resin yang terurai tersebut dapat di uji mikrostruktur dan komposisinya yaitu dengan alat uji SEM (Scanning Electron Microscope) dan EDS (Energy Dispersive X - Ray Spectroscopy) dimana sebuah spesimen difoto menggunakan mikroskop diberikan pembesaran jauh lebih tinggi mencapai 1.000.000 kali dengan kualitas gambar yang masih tampak jelas sedangkan EDS bertujuan untuk mengetahui unsur yang terkandung pada sampel yaitu dari unsur-unsur mulai dari litium (Li) sampai Uranium (U). Yoga Saputra (2019, h.4) berpendapat bahwa pengujian SEM dan EDS ini untuk mengetahui detail permukaan dari sambungan dan untuk mengetahui komposisi unsur dari material yang disambung. Serat yang diuji dalam pengujian EDS menggunakan serat yang terbuat dari alam yang bisa di ketahui unsur kimianya. Sifat mekanik suatu komposit diketahui melalui uji mekanik dimana pengeringan suatu spesimen komposit sebelum dilakukan pengujian adalah hal yang dapat mempengaruhi nilai maksimal dari sifat mekanik komposit tersebut. Penelitian ini untuk mengetahui nilai maksimal dari kekuatan tarik, kekuatan bending, mikrostruktur dan komposisi dari komposit serat pelepah pisang dengan waktu pengeringan selama 1 hari dan 7 hari. Selain itu dilakukan juga uji redam suara dari spesimen komposit tersebut yang kemudian dibandingkan dengan hasil uji redam suara dari glasswoll.

\section{Metode Penelitian}

Dalam penelitian ini dirancang sebuah material komposit dengan menggunakan serat alam pelepah pisang dan resin Fiber 157. Proses pembuatan spesimen menggunakan metode Vacuum Assisted Resin Inffusion. Setelah spesimen komposit terbentuk, maka dilakukan uji tarik, uji bending, uji komposisi dan mikrostruktur menggunakan alat uji Scaning Electron Microscope (SEM ) with Energy Dispersive Spectroscopy (EDS) dan uji peredam suara. Pembuatan komposit serat pelepah pisang dan semua pengujian dilakukan di laboratorium Komposit dan Material Teknik Departemen Aeronautika Akademi Angkatan Udara, Yogyakarta. Vacuum Assisted Resin Infusion adalah proses di mana rongga dalam tumpukan bahan berpori yang dievakuasi diisi dengan resin cair. Metode VARI menghasilkan material komposit yang mempunyai rasio fiber-resin yang tinggi dibandingkan dengan metode hand lay-up. Metode hand lay-up menggunakan cara manual untuk mengalirkan resin, sedangkan pada metode VARI aliran resin dilakukan oleh tekanan vakum yang konstan seperti pada gambar 1. Penggunaan tekanan vakum konstan ini yang mengatur distribusi resin agar tetap dalam suatu jumlah tertentu. Hal ini menyebabkan rasi fiber-resin menjadi tinggi sehingga menghasilkan material komposit yang lebih kuat dan ringan.
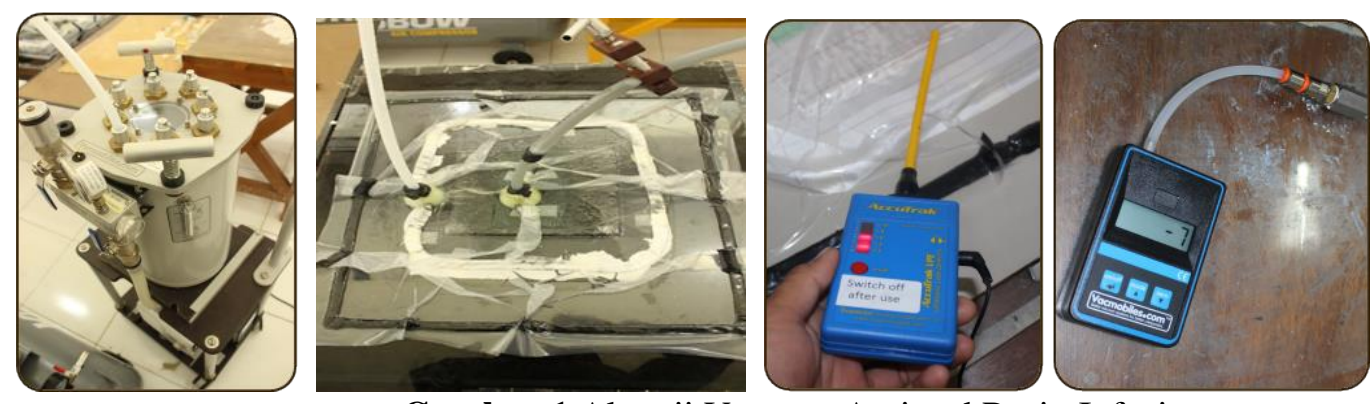

Gambar 1 Alat uji Vacuum Assisted Resin Infusion

Pengujian dilakukan dengan uji tarik, uji bending, uji mikrostruktur, uji komposisi dan uji redam suara seperti pada gambar 2 dan 3 . 

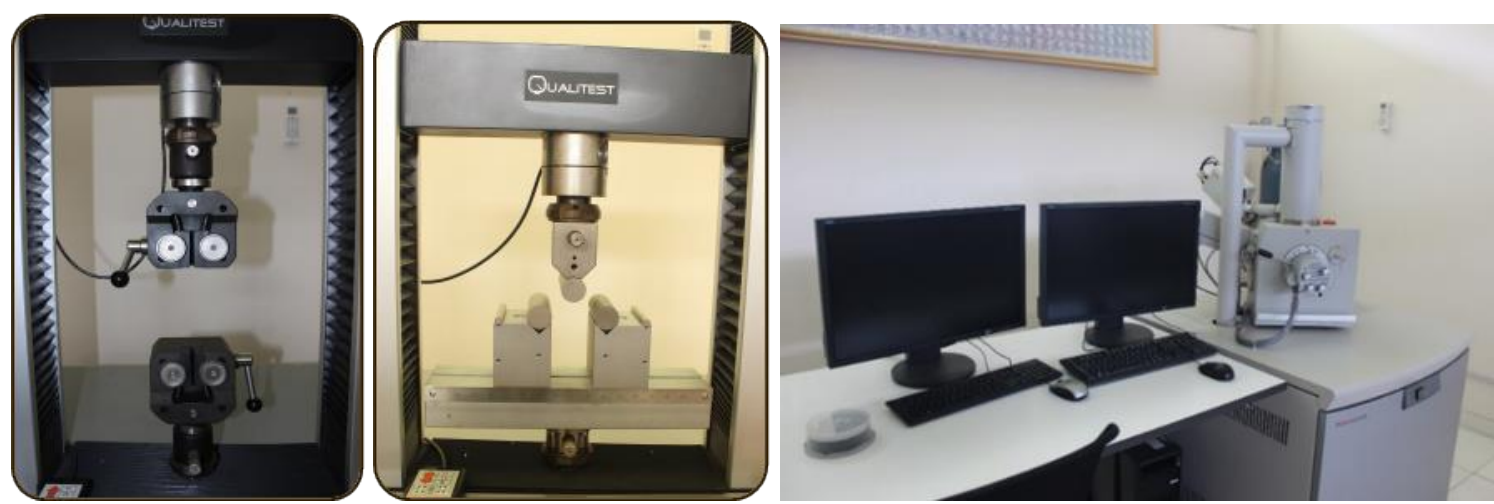

Gambar 2 Alat uji Tarik, Bending dan SEM EDS

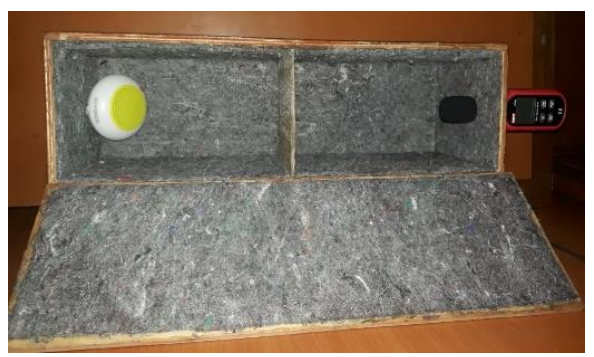

Gambar 3 Alat uji Redam Suara

Ukuran spesimen uji tarik yang digunakan sesuai Standart ASTM D 3039 / D 3039M (Sofyan Djamil , Sobron, dan Hartono 2014, h. 2).

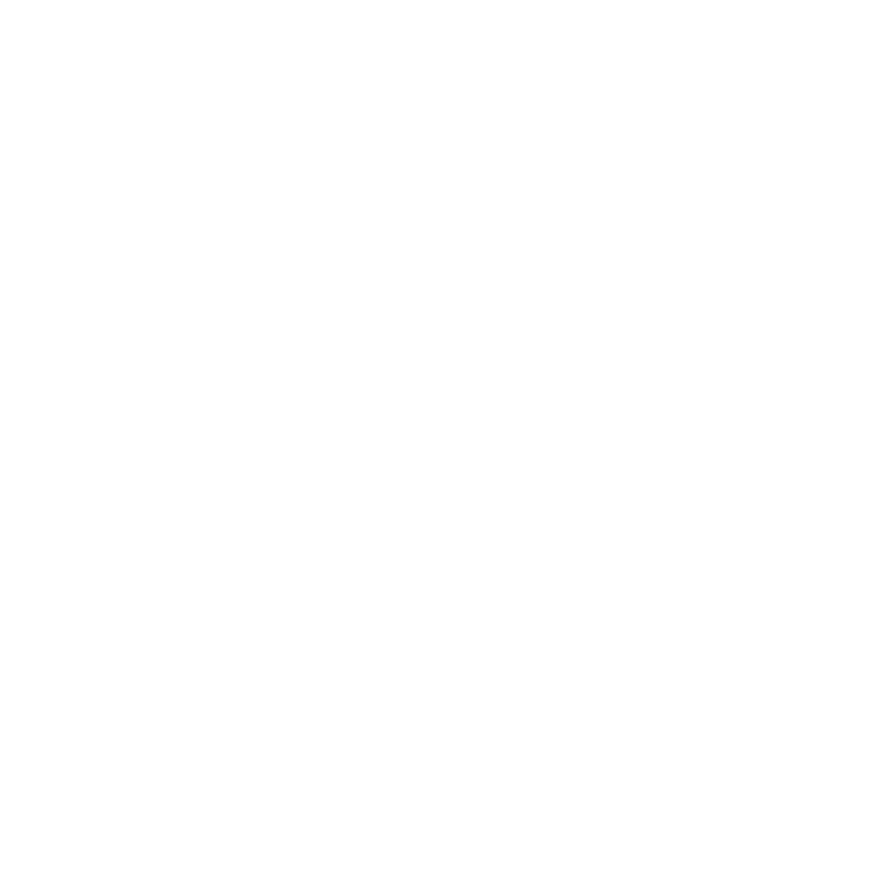

Gambar 4 Spesimen Uji Tarik Standart ASTM D 3039/ 3039 M

Pada tahap setelah pengujian tarik dapat dilihat pula bentuk patahan suatu komponen komposit yaitu dengan mengetahui macam-macam bentuk komposit seperti pada tabel 1 dan gambar 5 . 
Tabel 1 Karakter Kegagalan Uji Tarik Standart ASTM D 3039/ 3039 M 3039M

\begin{tabular}{|c|c|c|c|c|c|}
\hline \multicolumn{2}{|c|}{ KARAKTER 1} & \multicolumn{2}{|c|}{ KARAKTER 2} & \multicolumn{2}{|c|}{ KARAKTER 3} \\
\hline TIPE KEGAGALAN & KODE & KEGAGALAN AREA & KODE & KEGAGALAN LOKASI & KODE \\
\hline Miring & A & Sisi pegangan / tab & I & Bawah & $B$ \\
\hline Tepi Delaminasi & $D$ & Pada pegangan / tab & A & Atas & $T$ \\
\hline Pegangan / tab & G & $<1 W$ dari Tab pegangan & W & Kiri & L \\
\hline Lateral & $L$ & Pengukur & G & Kanan & $E$ \\
\hline Multi-mode & $M(x y s)$ & Beragam Area & $M$ & Tengah & M \\
\hline panjang. Pemisahan & $S$ & Beragam & V & Beragam & $\mathrm{V}$ \\
\hline eksplosif & $x$ & Tidak diketahui & $U$ & Tidak diketahui & U \\
\hline Lain & 0 & & & & \\
\hline
\end{tabular}

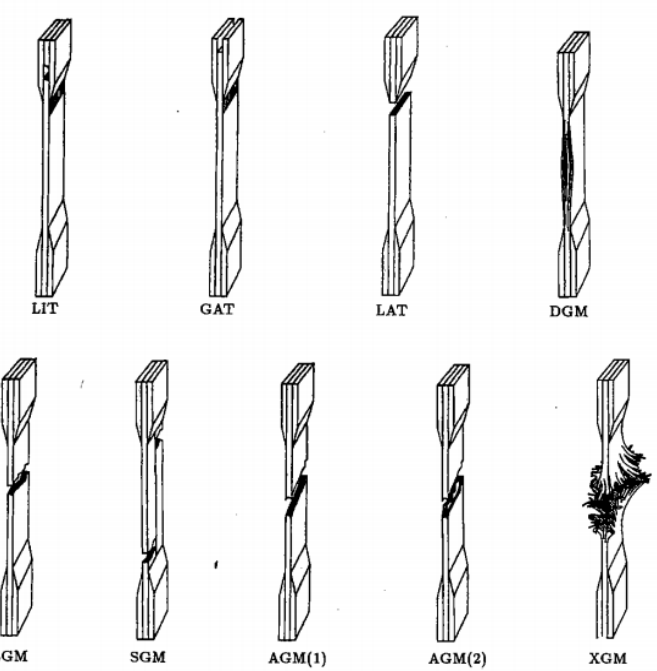

Gambar 5 Bentuk bentuk patahan pada uji tarik ASTM D 3039 / 3039M

\subsection{Tahap persiapan}

Sebelum membuat komposit persiapan yang dikumpulkan adalah menyiapkan alat dan bahan serta alkalisasi pada serat pelepah pisang dengan $\mathrm{NaOH} 5 \%$, yaitu :

1. Siapkan pelepah pisang yang sudah dipotong $20 \mathrm{~cm}$ memanjang.

2. Letakkan pelepah pisang pada suatu wadah.

3. Masukan $\mathrm{NaOH} 5 \%$ hingga semua permukaan terrendam.

4. Tunggu selama 2 jam.

5. Angkat pelepah pisang cuci di air mengalir lakukan berkali kali hingga $\mathrm{pH} 7$ / netral menggunakan lakmus.

6. Jemur di bawah sinar matahari hingga kering.

\subsection{Tahap Perancangan}

Langkah-langkah membuat komposit dengan Vacuum Assisted Resin Infusion, yaitu:

1. Siapkan vaccum bag, sealant tape, dan peel ply.

2. Siapkan serat pelepah pisang yg sudah kering.

3. Bersihkan alas dengan aseton hingga permukaan bersih, semprot dengan Scoth Supper.

4. Letakan serat dengan arah bi-directional $0^{\circ}$ dan $90^{\circ}$ semprot lagi tutup dengan peelply dan vacuum bag.

5. Rekatkan vacuum bag dengan sealant tape sehingga tidak ada udara.

6. Vakum terlebih dahulu agar vacuum bag dapat merekat dan rapat dengan spesimen, cek apakah terjadi kebocoran atau tidak dengan Vacuum gauge dan AccuTrack.

7. Siapkan resin dan hardener yang telah di ukur dengan perbandingan $300 \mathrm{ml} / 4,5 \mathrm{ml}$, aduk hingga rata.

8. Nyalakan vakum sehingga resin terhisap dan mengalir rata ke seluruh permukaan spesimen. 
9. Lama waktu pengeringan 8 jam. Setelah kering angkat.

10. Pembuatan vacuum assisted resin infusion sebanyak 3 kali (gambar 6).

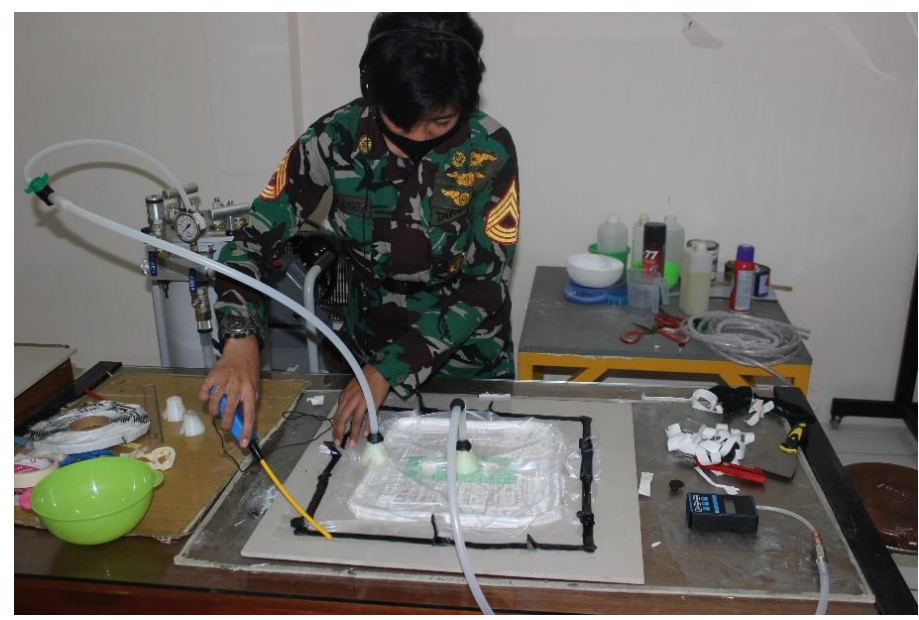

Gambar 6 Pembuatan Komposit dengan metode Vacuum Assisted Resin Infusion

2.3. Langkah langkah pembuatan kotak peredam suara

Lihat gambar 7, langkah-langkahnya sebagai berikut

1. Siapkan1cetakan komposit potong dengan ukuran $16 \times 16 \mathrm{~cm}$.

2. Siapkan papan triplek dengan ukuran 50x16 sebnayk 4 buah dan ukuran $16 \times 16 \mathrm{~cm}$ sebnyak 2 buah.

3. Lubangi sesuai dengan ukuran diameter sound level salah satu sisinya, sisi lain untuk meletakkan speaker box.

4. Rangkai sehingga terbentuk balok menggunakan paku.

5. Amplas permukaan dengan amplas kayu agar halus.

6. Lapisi dengan karpet peredam permukaan dalam dengan menngunakan lem.

7. Uji komposit diketahui tebal sama dengan glasswoll dan meletakan komposit sebagai skat (ditengah).

8. Catat berapa besarnya desibel suara.

9. Uji glaswoll catat berapa besarnya desibel suara.

10. Bandingkan antara spesimen komposit dengan bahan peredam aslinya yaitu glasswool.
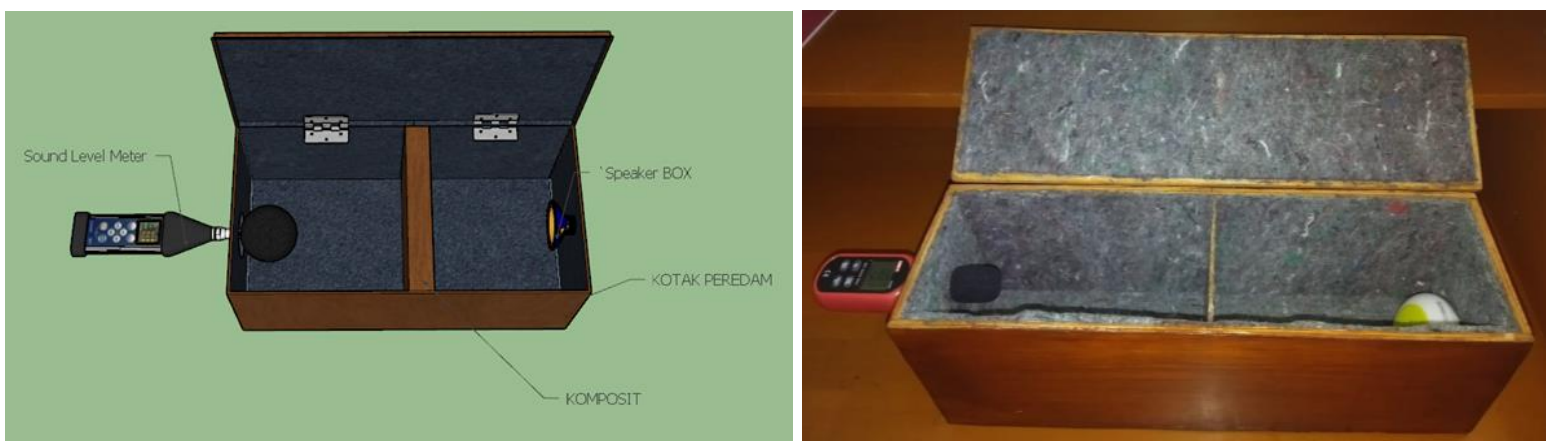

Gambar 7 Uji Peredam Suara 


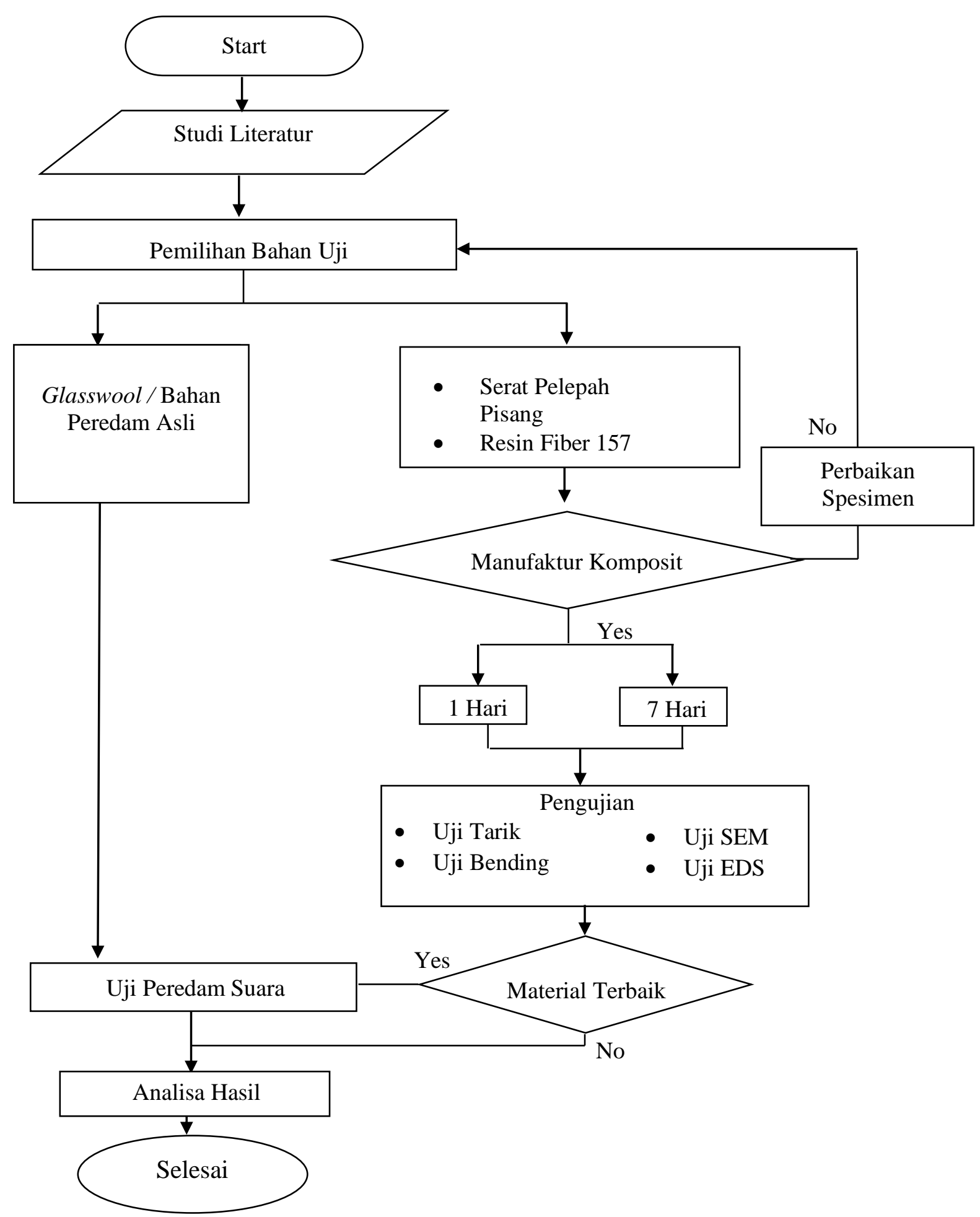

Gambar 8 Alur dalam penelitian

\subsection{Tahap Pengujian.}

Tahapan proses uji tarik, uji bending, SEM dan EDS adalah sebagai berikut :

1. Bahan komposit tiap percobaan di potong sesuai dengan ASTM yang berlaku.

2. Uji Tarik menggunakan ASTM D 3039/ 3039 M sebanyak 6 spesimen karena tiga spesimen untuk uji tarik dengan waktu pengeringan 1 hari dan tiga spesimen untuk uji tarik dengan waktu pengeringan 7 hari.

3. Uji bending menggunakan ASTM D790 03 dengan jumlah yang sama dengan uji tarik.

4. Setelah spesimen uji dipotong kemudian di haluskan dengan amplas halus terlebih dahulu.

5. Pengambilan data diambil berdasarkan nilai uji dari masing masing spesimen. 
6. Setelah data diperoleh, spesimen yang sudah di uji tarik di analisa dengan menggunakan Scaning Electron Microscope (SEM) dan Energy Dispersive Spectroscopy (EDS).

7. Setelah di uji tarik patahan dari pengujian tarik tersebut dapat di uji SEM dan EDS

\section{Hasil Pengujian}

\subsection{Pengujian Tarik.}

Berikut adalah data hasil uji tarik komposit serat pelepah pisang menggunakan metode Vacuum Assisted Resin Infusion dengan spesimen I dengan waktu pengeringan 7 hari ( Pembuatan hari Kamis pada tanggal 3 September 2020 dengan waktu pengerasan sampai tanggal 9 September 2020 ) dan Komposit II waktu pengeringan 1 hari (Pembuatan hari Jumát 4 September 2020 dengan waktu pengeringan sampai tanggal 5 September 2020) kemudian didapatkan uraian data berupa tabel 2, 3 dan 4 :

Tabel 2 Data Pengukuran Spesimen Uji Tarik

\begin{tabular}{|c|c|c|c|c|c|c|}
\hline \multirow{2}{*}{ No } & \multirow{2}{*}{ Spesimen } & $L_{o}$ & $w$ & $t$ & $A$ & $\Delta L$ \\
\hline & & $(\mathrm{mm})$ & $(\mathrm{mm})$ & $(\mathrm{mm})$ & $\left(\mathrm{mm}^{2}\right)$ & $(\mathrm{mm})$ \\
\hline 1 & IA & 150,00 & 25,00 & 5,20 & 130,00 & 4,00 \\
\hline 2 & IB & 150,00 & 24,80 & 4,90 & 121,52 & 3,50 \\
\hline 3 & IC & 150,00 & 24,10 & 5,00 & 120,50 & 3,70 \\
\hline 4 & IIA & 150,00 & 25,00 & 5,30 & 132,50 & 6,84 \\
\hline 5 & IIB & 150,00 & 24,90 & 4,90 & 122,01 & 7,00 \\
\hline 6 & IIC & 150,00 & 25,00 & 5,40 & 135,00 & 7,10 \\
\hline
\end{tabular}

Tabel 3 Data Hasil Uji Tarik

\begin{tabular}{cccccc}
\hline \multirow{2}{*}{ No } & Spesimen & Fmax & $\sigma \max$ & $E \max$ & E (Modulus Elastisitas) \\
\cline { 3 - 6 } & & $(\mathrm{N})$ & $\left(\mathrm{N} / \mathrm{mm}^{2}\right)$ & $($ Regangan) & $\left(\mathrm{N} / \mathrm{mm}^{2}\right)$ \\
\hline 1 & IA & 2525,33 & 19,42 & 0,027 & 728,25 \\
\hline 2 & IB & 2150,2 & 17,69 & 0,023 & 758,14 \\
\hline 3 & IC & 2000,58 & 16,60 & 0,025 & 672,97 \\
\hline 4 & IIA & 1937,67 & 14,62 & 0,046 & 320,61 \\
\hline 5 & IIB & 2441,41 & 20,01 & 0,047 & 428,79 \\
\hline 6 & IIC & 2098,02 & 15,54 & 0,047 & 328,31 \\
\hline
\end{tabular}


Tabel 4 Tabel Data Bentuk Patahan

\begin{tabular}{|c|c|c|c|c|c|}
\hline \multirow{2}{*}{ No } & \multirow{2}{*}{ Spesimen } & \multirow{2}{*}{$\begin{array}{l}\text { Bentuk } \\
\text { Patahan }\end{array}$} & \multicolumn{3}{|c|}{ Kegagalan } \\
\hline & & & Tipe & Area & Lokasi \\
\hline 1 & IA & $L A T$ & Lateral & Pada pegangan $(t a b)$ & Atas \\
\hline 2 & IB & $L A T$ & Lateral & Pada pegangan $(t a b)$ & Atas \\
\hline 3 & IC & $L A B$ & Lateral & Pada pegangan $(t a b)$ & Bawah \\
\hline 4 & IIA & $L A B$ & Lateral & Pada pegangan $(t a b)$ & Bawah \\
\hline 5 & IIB & $L A B$ & Lateral & Pada pegangan $(t a b)$ & Bawah \\
\hline 6 & IIC & $L A B$ & Lateral & Pada pegangan ( $t a b)$ & Bawah \\
\hline
\end{tabular}

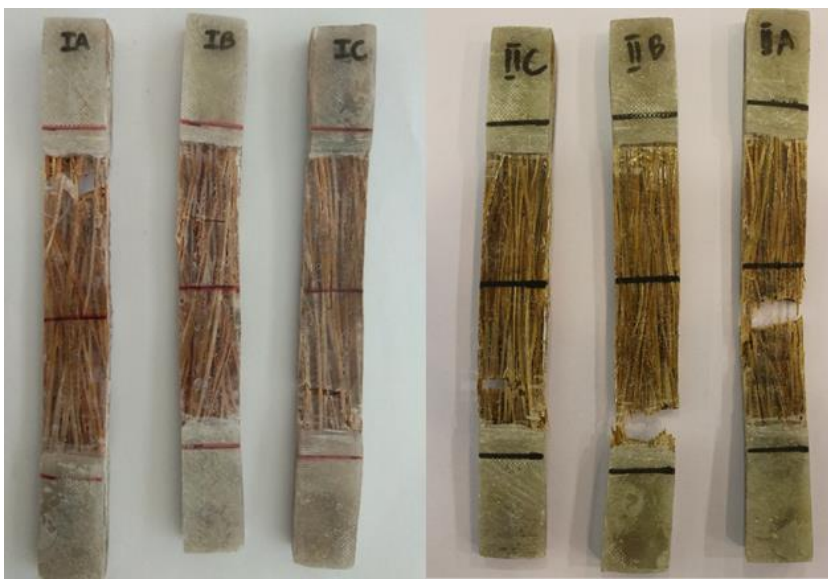

Gambar 9 Spesimen Uji Tarik Dengan Variasi Waktu 7 Hari Dan 1 Hari Setelah Pengujian

\subsection{Pengujian bending.}

Berikut adalah data hasil uji bending komposit serat pelepah pisang menggunakan metode Vacuum Assisted Resin Infusion dengan spesimen BI dengan waktu pengeringan 7 hari dan Komposit BII waktu pengeringan 1 hari kemudian didapatkan uraian data berupa tabel 5 :

Tabel 5. Hasil Pengukuran dan pengujian Spesimen Uji Bending

\begin{tabular}{ccccccc}
\hline \multirow{2}{*}{ No } & Spesimen & $\mathrm{L}$ & $\mathrm{B}$ & $\mathrm{h}$ & $\mathrm{P}$ & Bending \\
\cline { 3 - 7 } & & $(\mathrm{mm})$ & $(\mathrm{mm})$ & $(\mathrm{mm})$ & $(\mathrm{N})$ & $\left(\mathrm{N} / \mathrm{mm}^{2}\right)$ \\
\hline 1 & B IA & 62,00 & 13,00 & 5,10 & 104,5 & 28,741 \\
\hline 2 & B IB & 62,00 & 12,40 & 5,10 & 121,1 & 34,919 \\
\hline 3 & B IC & 62,00 & 12,40 & 5,10 & 109,5 & 31,574 \\
\hline 4 & B IIA & 62,00 & 12,00 & 5,30 & 85,60 & 23,616 \\
\hline 5 & B IIB & 62,00 & 13,00 & 4,90 & 69,80 & 20,797 \\
\hline 6 & B IIC & 62,00 & 12,90 & 5,10 & 63,60 & 17,628 \\
\hline
\end{tabular}




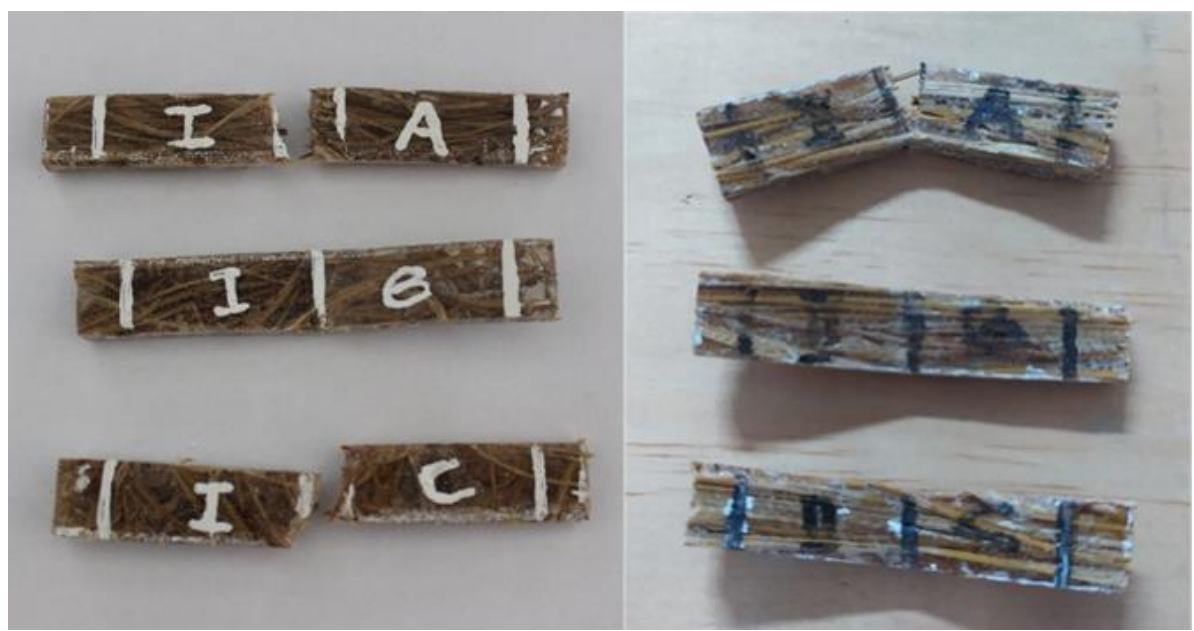

Gambar 10 Spesimen Uji Bending Dengan Variasi Waktu 7 Hari Dan 1 Hari Sesudah Pengujian.

\subsection{Pengujian Mikrostruktur dan Komposisi.}

Berdsarkan hasil penelitian struktur patahan dengan menggunakan Scanning Elecrton Microscopy adalah sebagai berikut: Terlihat pada kulit dari komposit serat pelepah pisang dengan waktu pengeringan selama 1 hari dengan metode Vaccum Assisted Resin Infusion terdapat perbedaan antara serat dengan resin, dimana serat pisang yang tampak memiliki rongga-rongga yang belum menjadi satu dengan resinnya dapat dilihat pada gambar 11. Terlihat pada kulit dari komposit serat pelepah pisang dengan waktu pengeringan selama 7 hari dengan metode Vaccum Assisted Resin Infusion terdapat perbedaan antara serat dengan resin, dimana serat pisang yang tampak memiliki rongga-rongga yang seluruh permukaannya hampir rata dan menjadi satu dengan resin dapat dilihat pada gambar 11 sebagai berikut :

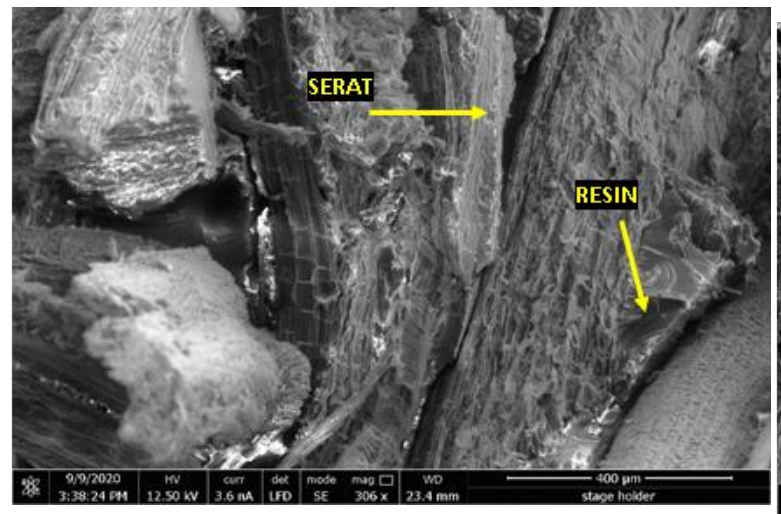

Gambar 11 Pengamatan Hasil Uji SEM 1 hari

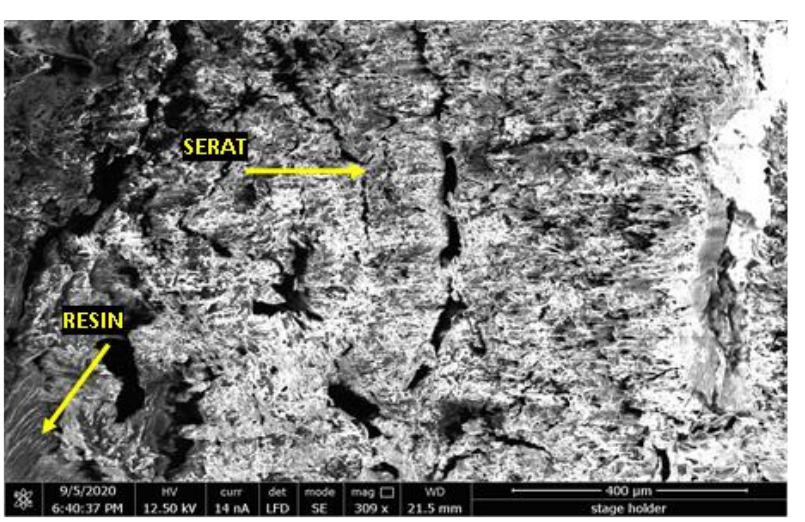

Gambar 11Pengamatan Hasil Uji SEM 7 hari

Berikut adalah data EDS setelah dilakukannya pengujian SEM yaitu data komposisi berupa hasil pengamatan yang dapat digunakan untuk dasar penjelasan dari uji SEM pada gambar 8 dan 9 diatas. Data tabel Komposisi dengan waktu pengeringan 7 hari dapat dilihat pada tabel 6 sedangkan data tabel komposisi dengan waktu pengeringan 1 hari dapat dilihat pada tabel 7. 
Tabel 6 Data Uji EDS Komposit 7 Hari

\begin{tabular}{cc}
\hline Element & Weight \% \\
\hline$C$ & 37.40 \\
\hline$O$ & 51.35 \\
\hline$N a$ & 4.72 \\
\hline$M g$ & 0.28 \\
\hline$A l$ & 0.47 \\
\hline$S i$ & 0.84 \\
\hline$P$ & 0.33 \\
\hline$S$ & 0.17 \\
\hline$C l$ & 0.60 \\
\hline$K$ & 2.11 \\
\hline$C a$ & 1.72 \\
\hline Total & 100,00 \\
\hline
\end{tabular}

Tabel 7 Data Uji EDS Komposit 1 Hari

\begin{tabular}{cc}
\hline Element & Weight \% \\
\hline$C$ & 41.45 \\
\hline$O$ & 52.00 \\
\hline$N a$ & 1.73 \\
\hline$M g$ & 0.48 \\
\hline$A l$ & 0.68 \\
\hline$S i$ & 0.89 \\
\hline$P$ & 0.20 \\
\hline$K$ & 0.36 \\
\hline$C a$ & 2.21 \\
\hline Total & 100.00 \\
\hline
\end{tabular}

Dari data uji EDS pada tabel diatas dapat mejelaskan bahwa komposit dengan waktu pengeringan 7 hari memiliki elemen oksigen lebih kecil yaitu dengan berat 51,35 \% dibandingkan dengan komposit dengan waktu pengeringan 1 hari yaitu 52,00\% .

3.4. Pengujian Peredam Suara. Berikut adalah data besar desible suara setelah dilakukannya pengujian peredam suara yaitu data berupa hasil pengujian yang dapat digunakan untuk dasar perbandingan : Data desibel adanya sumber suara dan tanpa sekat komposit pelepah pisang / glasswoll sebesar $103 \mathrm{~dB}$. Data taraf intensitas bunyi dalam desibel adanya suara dan komposit pelepah pisang menggunakan metode Vaccum Assisted Resin Infusion, sebagai berikut seperti pada tabel 8:

Tabel 8 Data Uji Redam Suara Dengan Sekat Komposit dan Glasswoll

\begin{tabular}{c|l}
\hline \multicolumn{2}{c}{ Komposit 7 } \\
hari \\
\hline Pengambilan data & \multicolumn{1}{c}{$\mathrm{I}(\mathrm{dB})$} \\
\hline 1 & 89,2 \\
\hline 2 & 89,9 \\
\hline 3 & 89,1 \\
\hline 4 & 90,1 \\
\hline 5 & 89,0 \\
\hline RATA - RATA & 89,5 \\
\hline
\end{tabular}

\begin{tabular}{c|c}
\multicolumn{2}{c}{ Glasswoll } \\
\hline Pengambilan data & TI (dB) \\
\hline 1 & 91,3 \\
\hline 2 & 92,2 \\
\hline 3 & 94,4 \\
\hline 4 & 91,0 \\
\hline 5 & 89,6 \\
\hline RATA - RATA & 91,7 \\
\hline
\end{tabular}

Dari data uji peredam suara pada tabel 8 menjelaskan bahwa uji suara dengan menggunakan sekat komposit memiliki taraf intesitas suara rata-rata $89,5 \mathrm{~dB}$ lebih kecil dibandingkan dengan sekat menggunakan peredam asli yaitu dengan intensitas suara 91,7 dB.

\section{Analisis}

4.1. Uji tarik.

Berdasarkan hasil uji tegangan tarik dapat diuji sebanyak 3 spesimen yaitu spesimen IA dengan nilai $19,42 \mathrm{~N} / \mathrm{mm}^{2}$, spesimen IB dengan nilai $17,69 \mathrm{~N} / \mathrm{mm}^{2}$, dan spesimen IC dengan nilai $16,6 \mathrm{~N} / \mathrm{mm}^{2}$ didapatkan nilai rata-rata 3 spesimen tegangan uji tarik I yaitu dengan rata-rata sebesar 17,90 N/mm². Spesimen 7 hari lebih unggul dibandingkan 1 hari yaitu spesimen IIA dengan nilai $14,62 \mathrm{~N} / \mathrm{mm}^{2}$, spesimen IIB dengan nilai 20,01, spesimen IIC dengan nilai 15,54 dengan nilai rata-rata sebesar rata-rata 
sebesar $16,72 \mathrm{~N} / \mathrm{mm}^{2}$. Selanjutnya berdasarkan hasil perhitungan regangan pada spesimen IA dengan nilai 0,027, spesimen IB dengan nilai 0,023, spesimen IC dengan nilai 0,025 dapat ditentukan bahwa nilai ratarata regangan pada spesimen 7 hari dengan nilai $0,025 \mathrm{~N} / \mathrm{mm}^{2}$. Berdasarkan hasil perhitungan regangan pada spesimen IIA dengan nilai 0,046 , spesimen IB dengan nilai 0,047 , spesimen IC dengan nilai 0,047 dapat ditentukan bahwa nilai rata-rata regangan pada spesimen 1 hari dengan nilai $0,047 \mathrm{~N} / \mathrm{mm}^{2}$, maka nilai waktu pengeringan 7 hari memiliki nilai regangan lebih kecil yaitu 0,025 dibandingkan dengan spesimen komposit serat pelepah pisang dengan waktu pengeringan 1 hari yaitu 0,047. Setelah diperoleh nilai tegangan dan regangan pada masing-masing spesimen, maka nilai modulus elastisitas pada tiap-tiap spesimen dapat ditentukan. Hasil perhitungan nilai modulus elastisitas dapat dilihat pada tabel 3 . Berdasarkan data tersebut, dapat ditunjukkan bahwa modulus elastisitas spesimen komposit serat pelepah pisang dengan waktu pengeringan 7 hari pada spesimen IA dengan nilai $728,25 \mathrm{~N} / \mathrm{mm}^{2}$, spesimen IB dengan nilai $758,14 \mathrm{~N} / \mathrm{mm}^{2}$, spesimen IC dengan nilai $672,97 \mathrm{~N} / \mathrm{mm}^{2}$. Selanjutnya modulus elastisitas spesimen komposit serat pelepah pisang dengan waktu pengeringan 1 hari pada spesimen IIA dengan nilai $320,61 \mathrm{~N} / \mathrm{mm}^{2}$, spesimen IIB dengan nilai 428,79 , spesimen IIC dengan nilai $328,31 \mathrm{~N} / \mathrm{mm}^{2}$. Spesimen dengan waktu pengeringan 7 hari memiliki nilai rata-rata lebih unggul dibanding spesimen 1 hari yaitu $719,79 \mathrm{~N} / \mathrm{mm} 2$,sedangkan spesimen komposit serat pelepah pisang dengan waktu pengeringan 1 hari memiliki nilai lebih rendah yaitu $359,24 \mathrm{~N} / \mathrm{mm}^{2}$.

Analisis bentuk patahan dapat diketahui bahwa dari komposit I dengan waktu pengeringan 7 hari bentuk patahan mendominasi pada jenis LAT di area atas spesimen, sedangkan jenis patahan pada komposit II dengan waktu pengeringan 1 hari mendominasi pada jenis LAB di area bawah spesimen.

Dapat diketahui hasil nilai yang ada dari setiap hasil perhitungan pengujian tarik tegangan, regangan dan modulus elastisitas bahwa spesimen dengan waktu pengeringan 7 hari memiliki nilai yang lebih unggul dibandingkan spesimen dengan waktu pengeringan 1 hari, dapat dilihat dari tegangan dan modulus elastisitasnya semakin besar nilai tegangan dan modulus elastisitas maka semakin keras suatu spesimen, dan untuk nilai regangan tarik semakin kecil nilai regangannya maka semakin keras suatu spesimen komposit.

\subsection{Uji bending.}

Pengujian kekuatan bending pada tabel 5, ditunjukkan nilai kekuatan bending maksimal spesimen komposit serat pelepah pisang dengan waktu pengeringan selama 7 hari pada spesimen BIA dengan nilai $28,74 \mathrm{~N} / \mathrm{mm}^{2}$, spesimen BIB dengan nilai $34,92 \mathrm{~N} / \mathrm{mm}^{2}$, dan spesimen BIC dengan nilai $31,57 \mathrm{~N} / \mathrm{mm}^{2}$ dimana nilai rata-rata dengan waktu pengeringan 7 hari memiliki nilai $31,75 \mathrm{~N} / \mathrm{mm}^{2}$. Nilai kekuatan bending maksimal spesimen komposit serat pelepah pisang dengan waktu pengeringan selama 1 hari pada

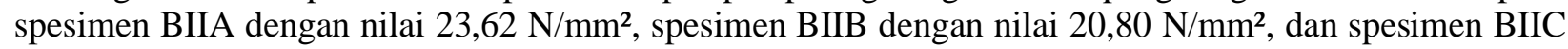
dengan nilai $17,63 \mathrm{~N} / \mathrm{mm}^{2}$ dimana nilai rata-rata dengan waktu pengerasan 1 hari memiliki nilai 20,68 $\mathrm{N} / \mathrm{mm}^{2}$. Spesimen komposit dengan waktu 7 hari memiliki nilai kekuatan bending rata-rata lebih unggul dari pada 1 hari.

\subsection{Uji Mikrostruktur dan Komposisi.}

Pada pengujian mikrostruktur menggunakan SEM didapatkan data berupa gambar yaitu pada gambar 8 dan 9 dengan pembesaran dapat dilihat gambar komposit dengan serat pelepah pisang dengan waktu pengeringan 7 hari struktur permukaan lebih rapat dan tidak banyak rongga antara resin dan serat atau lebih menyatu antara resin dan serat sedangkan pada komposit dengan serat pelepah pisang dengan waktu pengeringan 1 hari masih terlihat banyaknya rongga antara serat dengan resin yang tidak rata. Pada pengujian EDS didapatkan data berupa tabel 6 dan 7, pada tabel tersebut menjelaskan bahwa komposit dengan waktu pengeringan 7 hari memiliki elemen oksigen lebih kecil yaitu dengan berat 51,35\% dibandingkan dengan komposit dengan waktu pengeringan 1 hari yaitu 52,00\%. Oksigen dan uap air terdapat pada ronga-ronga spesimen komposit dimana adanya udara pada celah diantara resin dan serat, namun udara tersebut berkurang karena adanya penguapan dimana penguapan membutuhkan waktu pada suatu proses pengerasan spesimen komposit. Akibatnya unsur oksigen dan uap air terkandung dalam material komposit berkurang karena penurunan kadar air dan adanya proses penguapan dapat dilihat dari pengujian SEM dan EDS bahwa semakin diberi waktu 7 hari pada proses pengerasan spesimen komposit 
maka oksigen dan uap air semakin berkurang karena adanya proses penguapan dan permukaan spesimen lebih sedikit rongganya.

4.4. Uji peredam suara. Selanjutnya pada pengujian peredam suara didapatkan data berupa tabel 8 dengan pengambilan data sebanyak 5 kali yaitu pada komposit dengan waktu pengeringan 7 hari pengambilan spesimen yang pertama sebesar 89,2 db, pada pengambilan data yang kedua sebesar 89,9 db, pada pengambilan yang ketiga sebesar $89,1 \mathrm{db}$, pada pengambilan yang keempat sebesar $90,1 \mathrm{db}$, dan pada pengambilan data yang kelima sebesar $89,0 \mathrm{db}$, dengan nilai rata-rata uji peredam suara pada komposit 7 hari yaitu sebesar $89,5 \mathrm{db}$.

Pada pengujian peredam suara bahan peredam asli / glasswoll didapatkan data berupa tabel 8 dengan pengambilan data sebanyak 5 kali yaitu pada pengambilan yang pertama sebesar $91,3 \mathrm{db}$, pada pengambilan data yang kedua sebesar 92,2 db, pada pengambilan yang ketiga sebesar 94,4 db, pada pengambilan yang keempat sebesar 91,0 db, dan pada pengambilan data yang kelima sebesar 89,6 db, dengan nilai rata-rata uji peredam suara pada glasswoll yaitu sebesar 91,7 db. Pengujian peredam suara pada komposit dengan waktu pengeringan 7 hari lebih baik dibandingkan peredam aslinya yaitu glasswoll.

\section{Kesimpulan}

Hasil dari penelitian ini diperoleh kekuatan tegangan tarik yang dihasilkan oleh komposit serat pelepah pisang dengan waktu pengeringan selama 7 hari adalah sebesar $17,90 \mathrm{~N} / \mathrm{mm}^{2}$ sedangkan waktu pengeringan selama 1 hari adalah sebesar $16,72 \mathrm{~N} / \mathrm{mm}^{2}$. Hasil dari spesimen 7 hari menunjukan 7,05\% lebih besar di bandingkan dengan 1 hari. Regangan tarik yang dihasilkan oleh komposit serat pelepah pisang dengan waktu pengerasan selama 7 hari adalah sebesar 0,025 sedangkan waktu pengerasan selama 1 hari adalah sebesar 0,047. Modulus elastisistas yang dihasilkan oleh komposit serat pelepah pisang dengan waktu pengerasan selama 7 hari adalah sebesar $719,79 \mathrm{~N} / \mathrm{mm}^{2}$ sedangkan waktu pengerasan selama 1 hari adalah sebesar 359,244 N/mm ${ }^{2}$. Bentuk patahan spesimen 7 hari dan 1 hari di dominasi pada bagian pegangan tab atas dan bawah. Kekuatan bending yang dihasilkan oleh komposit serat pelepah pisang dengan waktu pengeringan selama 7 hari adalah sebesar $31,75 \mathrm{~N} / \mathrm{mm}^{2}$ sedangkan waktu pengeringan selama 1 hari adalah sebesar 20,68 N/mm $\mathrm{mm}^{2}$. Hasil dari spesimen 7 hari menunjukan $54 \%$ lebih besar di banding dengan 1 hari. Hasil mikrostruktur pada komposit serat pelepah pisang dengan waktu pengeringan selama 7 hari terlihat serat dan resin lebih menyatu dibandingkan waktu pengeringan selama 1 hari dimana serat dan resin kurang menyatu serta masih banyak ronga udara. Uji komposisi diperoleh jumlah oksigen pada komposit serat pelepah pisang dengan waktu pengeringan selama 1 hari yaitu $52,00 \%$ sedangkan waktu pengeringan selama 7 hari yaitu $51,35 \%$. Sehingga dari hasil semua uji sifat mekanik tersebut disimpulkan bahwa untuk memperoleh nilai sifat mekanik yang maksimal dari suatu komposit yang dibuat, maka komposit agar dikeringkan terebih dahulu selama 7 hari sebelum dilaksanakan pengujian. Pada penelitian ini juga diperoleh hasil desibel suara tanpa adanya sekat atau ruangan kosong dengan diberi suara sebesar $103 \mathrm{~dB}$ sehingga dapat disimpulkan bahwa hasil uji peredam suara komposit pelepah pisang dengan waktu pengeringan selama 7 hari mampu meredam suara sebesar $21 \%$ dengan taraf intensitas suara $89,5 \mathrm{~dB}$ sedangkan glasswoll memberikan peredaman suara sebesar $8,76 \%$ dengan nilai taraf intensitasnya $91,7 \mathrm{~dB}$.

\section{Daftar Pustaka}

[1] Kardiman,dkk, Maret 2018" Analisis Sifat Mekanik Terhadap Bentuk Morfologi Papan Komposit Sekam Padi sebagai Material Alternatif Pengganti Serat Kaca", Jurnal Riset Sains dan Teknologi Volume 2 No. 1

[2] Mohammad Alfian,dkk, "Pengaruh Fraksi Volume Fiber Glass Terhadap Sifat Mekanik Komposit Fiber Glass/Epoxy Dengan Metode Vari", Jurnal Stator, diakses dari Januari 2020.

[3] Yoga Saputro, Mei 2019 "Analisis Scanning Electron Microscope (SEM) Pada Pengelasan Brazing Antara Aluminium Seri 1000 Dan Stainless Steel Seri 304 Dengan Penambahan Serbuk Tembaga" Jurnal Teknik Mesin.

[4] Ridway Balaka,dkk. , Mei 2016"Analisa Mampu Redam Suara Pada Material Komposit Kalsiboard Dan Gypsum”, Jurnal Ilmiah Mahasiswa Teknik Mesin, Vol. 1, No.1. 
[5] Harsi,dkk. , Juli 2015" Karakteristik Kekuatan Bending Dan Kekuatan Tekan Komposit Serat Hybrid Kapas/Gelas Sebagai Pengganti Produk Kayu”, Dinamika Teknik Mesin, Vol. 5, No. 2.

[6] Indra Mawardi, Hasrin Lubis, 2019, Proses Manufaktur Plastik dan Komposit. Penerbit Andi.

[7] Sofyan dkk, April 2014” Kekuatan Tarik Komposit Matrik Polimer Berpenguat Serat Alam Bambu Gigantochloa Apus Jenis Anyaman Diamond Braid dan Plain Weave" Jurnal Energi dan Manufaktur Vol.7, No.1: 1-118.

[8] I Gede Widiartha, dkk, 2012 "Study Kekuatan Bending dan Struktur Mikro Komposit Polyethylene Yang Diperkuat oleh Hybrid Serat Sisal dan Kurang Goni”, Dinamika Teknik Mesin, Volume 2 No. 2 Juli 2012, Universitas Mataram, Mataram.

[9] Vacmobile, 2020, "Vacuum systems for composites ready to inifuse, right out of the box ",hlm 2 dan 5-7.

[10] Kunartto,dkk. 2018 "Serat Pelepah Pisang Dan Eceng Gondok Sebagai Penguat Komposit Dengan Variasi Arah Serat Terhadap Uji Tarik Dan Bending”, Jurnal Teknik Mesin Ubl, Vol.5 No. 2.

[11] Michael C. Y. Niu, 2000 Composite Airframe Structure, Hongkong Conmilit Press LTD. 
